\title{
"A study of Serum levels of LDH and ALP in carcinoma breast: An Observational study"
}

\author{
Dr Vijay Shrivastava ${ }^{1}$, Dr Pratibha Meena ${ }^{2}$, Dr Radhika Nandwani ${ }^{3}$, \\ Dr Shailendra Meena ${ }^{4}$ \\ ${ }^{I}$ Professor, Department of Pathology, Netaji Subhash Chandra Bose Medical College, Jabalpur, Madhya \\ Pradesh , India. \\ ${ }^{2}$ Post graduate student, Department of Pathology, Netaji Subhash Chandra Bose Medical College, Jabalpur, \\ Madhya Pradesh, India. \\ ${ }^{3}$ Assistant Professor, Department of Pathology, Netaji Subhash Chandra Bose Medical College, Jabalpur, \\ Madhya Pradesh, India. \\ ${ }^{4}$ Post graduate student, Department of Community Medicine, L N Medical college and research centre, Bhopal, \\ Madhya Pradesh.
}

\begin{abstract}
:
Background:- Breast Cancer is one of the major surgical problems in India particularly among the younger women. Unfortunately, most breast cancers do not produce any symptoms until the tumors are either too large to be removed surgically or cancerous cells have already spread to other tissues i.e. metastasis has taken place. Therefore, there is a need for noninvasive and sensitive methods to detect growths small in size which escape routine examination. There is, therefore, need of simple investigations, which can be easily assayed, are less expensive and can detect metastasis.

Aims And Objectives: To study the serum levels of $L D H$ and ALP in cases of breast lesions and to evaluate whether their levels are significantly higher in cases of breast malignancies as compared to cases of benign breast lesions

Material And Methods:- A total number of 160 subjects were studied, comprising of 80 cases of benign breast lesions and 80 Breast cancer subjects. Breast cancer subjects were further divided depending on stage of the cancer. Serum levels of $L D H$ and ALP were estimated in all the subjects.

RESULT:- The present observational study has shown a significant elevation in serum levels of LDH and ALP in cases of carcinoma Breast as compared to benign breast lesions. These levels raised significantly with severity (stage) of carcinoma Breast.

Conclusion:- Serum LDH and ALP may serve as biomarkers in carcinoma breast and may help in early detection of progression of the disease. These enzymes can be easily assayed in laboratories that do not have sophisticated technologies.
\end{abstract}

Keywords: Alkaline Phosphatase, Breast carcinoma, Fibroadenoma, Lactate Dehydrogenase.

\section{Introduction}

Breast Cancer is one of the major surgical problems in India particularly among the younger women. There is increase in prevalence of Breast cancer in developed as well as developing countries .Various theories are proposed, based on altered hormonal milieu, personal and demographic factors. ${ }^{1}$ Unfortunatey in most of the cases of cancer, symptoms are not produced until the tumors are either too large to be removed surgically or metastasis has taken place. ${ }^{2}$

In normal physiological conditions each tissue maintains a steady and consistent enzymatic pattern which is altered significantly in malignancy as the constituents are shed into surrounding milieu at an increased rate when cells replicate more rapidly. Cancer is a proliferative and invasive disease and tumor cells respire anaerobically. ${ }^{3}$ Increased glycolysis is mostly observed in cancer cells. ${ }^{4}$ Tumor associated markers reflect behavioral changes from tissue to blood, resulting in changes in levels of enzymes, proteins and hormones both in cancerous tissue and blood because of unchecked proliferation of cells. Therefore, alteration in particular enzyme contents in serum could be a good index of malignancy in its early and best manageable stage. ${ }^{5}$

Several tumor markers are available these days. However, the analytical methods of many of these are unapproachable for general population as facilities for these are available only at sophisticated and well equipped centres with latest technology and are expensive. There is therefore need for simple biochemical investigations which can be easily assayed, are less expensive and can detect metastases. ${ }^{2}$ 
Hence, present study was undertaken to evaluate the importance of assessing the serum levels of Lactate Dehydrogenase (LDH) and Alkaline Phosphatase (ALP) in patients of carcinoma breast and also to correlate probable relationship between serum levels of these tumor markers and stages of breast cancer.

\section{Aims \&Objectives}

1) To study the serum levels of Lactate Dehydrogenase and Alkaline Phosphatase in cases of benign and malignant breast lesions.

2) To evaluate whether the serum levels of Lactate Dehydrogenas and Alkaline Phosphatase are significantly higher in cases of breast malignancies as compared to cases of benign breast lesions.

3) To evaluate whether the serum levels of Lactate Dehydrogenase and Alkaline Phosphatase are significantly correlated with stage of the disease in cases of malignant breast lesions.

\section{Materials and methods}

1. STUDY DESIGN: Observational Study.

2. STUDY PERIOD: November 2014 to November 2015.

3. STUDY PLACE: Department of Pathology, N.S.C.B. MEDICAL COLLEGE AND HOSPITAL, JABALPUR.

4. SAMPLE SIZE DETERMINATION: Sample size was calculated by using power and sample size command (sampsi) in STATA 12 (StatCorp LP, Texas USA) statistical software. The assumptions for comparing the mean difference of LDH and ALP between benign and malignant group was considered $20-60$. Minimum required samples size was drawn 71 cases in each group with 5\% alpha and $80 \%$ power. To adjust the non-response error which assumed maximum up to $10 \%$, the sample size was further increased and finally we decided to enroll 80 sample in each group.

5. RECRUITMENT OF STUDY PARTICIPANTS: A total number of 160 subjects participated in the present study which included 80 cases each of benign and malignant lesions of the breast. All were in the age group of 18 to 80 years. Study was conducted on inpatients and out patients of N.S.C.B. MEDICAL COLLEGE AND HOSPITAL, JABALPUR. Cases were histopathologically or cytologically diagnosed as benign and malignant lesions of the breast. After taking informed consent, a careful history was taken and thorough clinical examination was conducted in all the cases. Serum LDH and ALP levels were measured and complete blood count (including hemoglobin, platelets, total and differential leucocyte count ) was done in all the cases.

\section{INCLUSION CRITERIA:}

Patients with Breast lesions from inpatient and outpatient department of N.S.C.B. MEDICAL COLLEGE AND HOSPITAL, JABALPUR, in the age group of 18 to 80 years. Study subjects were divided into two subgroups :

- Group 1: Patients having Benign breast lesion.

- Group 2: Patients having malignant Breast lesion.

The cases were proven as benign and malignant cytologically or histopathologically. Breast malignancy patients were further divided according to stage grouping. Stage grouping was based on TNM staging system.

\section{EXCLUSION CRITERIA:}

Patients with

- Myocardial infarction.

- Liver disease.

- History of Alcoholism.

- Pancreatic disease.

- Bone diseases other than metastasis.

- Diabetes mellitus.

- Other malignancies.

- Those taking anti-epileptic or hepatotoxic drugs during the last three months were excluded from the study.

8. ETHICAL CONSIDERATION: This study was approved by the Research and Ethical Committee of NSCB MEDICAL COLLEGE AND HOSPITAL, JABALPUR.

\section{Results}

The present study included 80 cases of each benign and malignant lesions of breast (total 160 cases) confirmed cytologically or histopathologically during the period november 2014 to november 2015 in department of pathology , NSCB Medical College and Hospital , Jabalpur. 
On distributing cases according to age it was seen that most lesions were in reproductive age group . In present study maximum cases of malignant lesions were in $40-49$ years of age group(i.e. 52.5\% ) followed by $30-39$ years of age group (i.e.15\% ) and there were no cases in $<20$ years of age group. Maximum number of cases of benign lesions were in $20-29$ years of age group (i.e.33.8\%), followed by $30-39$ years of age group i.e. $(31.3 \%)$.In $>50$ years of age group there were only 3 cases of benign lesion i.e. $3.6 \%$ (table 1).

In rural area there were more number of cases of malignant lesions $(61 \%)$ than benign lesions $(39 \%)$. In urban area benign lesions were more common (60.2\%) than malignant lesions (39.8\%) (table 2).

In present study the mean serum levels of $\mathrm{LDH}$ was raised in cases of Malignant lesions when compared to cases of Benign lesions, and the rise was highly significant ( $\mathrm{p}$ value $<0.001$ ) (table 3). The mean levels of serum LDH increased serially from stage I to stage IV in the present study (table 4). When serum LDH levels were compared in different stages of breast cancer the enzyme levels increased significantly as the disease progressed from stage II to stage IV .However no significant difference was observed in the enzyme level when stage I was compared with benign disease (table 5).

In the present study the mean serum levels of ALP were significantly raised (p value 0.001 ) in cases of malignant lesions when compared to those of benign lesions (table 6). The mean levels of serum ALP increased serially from stage I to stage IV in the present study. Highest enzyme level was observed in stage IV of the disease (table 7). Although mean serum ALP levels increased serially from stage I to stage IV in patients with malignant lesions, significant elevation was seen only in cases with stage $I V$ disease when compared to other stages in present study, and there was no significant difference observed in the enzyme level when stage I was compared with benign disease (table 8).

In present study serum levels of LDH were higher in malignant lesions when compared to benign lesions with comparable size of the tumor (table 9). Serum levels of ALP were also higher in malignant lesions when compared to benign lesions with comparable size of the tumor (table 10).

Table 1: Age wise distribution of tumors:

\begin{tabular}{|c|c|c|c|}
\hline \multirow{2}{*}{ Age } & \multicolumn{2}{|c|}{ Breast Tumour } & \multirow{2}{*}{ Total } \\
\hline & Malignant & Benign & \\
\hline \multirow{2}{*}{$<20$} & 0 & 13 & 13 \\
\hline & $0.0 \%$ & $16.3 \%$ & $8.1 \%$ \\
\hline \multirow{2}{*}{$20-29$} & 3 & 27 & 30 \\
\hline & $3.8 \%$ & $33.8 \%$ & $18.8 \%$ \\
\hline \multirow{2}{*}{$30-39$} & 12 & 25 & 37 \\
\hline & $15.0 \%$ & $31.3 \%$ & $23.1 \%$ \\
\hline \multirow{2}{*}{$40-49$} & 42 & 12 & 54 \\
\hline & $52.5 \%$ & $15.0 \%$ & $33.8 \%$ \\
\hline \multirow{2}{*}{$50-59$} & 10 & 2 & 12 \\
\hline & $12.5 \%$ & $2.5 \%$ & $7.5 \%$ \\
\hline \multirow{2}{*}{$60-69$} & 6 & 1 & 7 \\
\hline & $7.5 \%$ & $1.3 \%$ & $4.4 \%$ \\
\hline \multirow{2}{*}{$>70$} & 7 & 0 & 7 \\
\hline & $8.8 \%$ & $0.0 \%$ & $4.4 \%$ \\
\hline \multirow{2}{*}{ Total } & 80 & 80 & 160 \\
\hline & $100.0 \%$ & $100.0 \%$ & $100.0 \%$ \\
\hline
\end{tabular}

Table 2: Distribution of tumors according to place of residence :

\begin{tabular}{|c|c|c|c|}
\hline \multirow{2}{*}{ Residence } & \multicolumn{2}{|c|}{ Breast Tumour } & \multirow{2}{*}{ Total } \\
\cline { 2 - 4 } & Malignant & 30 & 77 \\
\hline \multirow{2}{*}{ Rural } & 47 & $39.0 \%$ & $100.0 \%$ \\
\cline { 2 - 4 } & $61.0 \%$ & 50 & 83 \\
\hline \multirow{2}{*}{ Urban } & 33 & $60.2 \%$ & $100.0 \%$ \\
\cline { 2 - 4 } & $39.8 \%$ & 80 & 160 \\
\hline \multirow{2}{*}{ Total } & 80 & $50.0 \%$ & $100.0 \%$ \\
\cline { 2 - 4 } & $50.0 \%$ & & \\
\hline
\end{tabular}

$\mathbf{P}=\mathbf{. 0 0 7}$

Table 3: Comparison of LDH levels in malignant and benign breast tumours :

\begin{tabular}{|c|c|c|c|c|c|}
\hline & \multicolumn{2}{|c|}{ Malignant } & \multicolumn{2}{|c|}{ Benign } & p value \\
\cline { 2 - 6 } & Mean & Std. Deviation & Mean & Std. Deviation & 110.29 \\
\hline Serum LDH Level & 673.10 & 221.35 & 494.69 & $<0.001$ \\
\hline
\end{tabular}


Table 4: Mean Serum LDH Level according to the clinical stage :

\begin{tabular}{|l|c|c|c|}
\hline Stage & Mean Serum LDH & Std. Deviation & No of patients \\
\hline I & 471.67 & 149.70 & 3 \\
\hline II & 530.23 & 137.56 & 31 \\
\hline III & 743.70 & 207.57 & 37 \\
\hline IV & 942.11 & 120.88 & 9 \\
\hline
\end{tabular}

Table 5: Comparison of Mean Serum LDH Level in different clinical stages of breast cancer patients :

\begin{tabular}{|l|l|}
\hline LDH mean & P value \\
\hline Benign Vs stage I & 0.81 \\
\hline Stage I Vs Stage II & 0.57 \\
\hline Stage I Vs Stage III & 0.071 \\
\hline Stage I Vs Stage IV & $0.017[\mathrm{sig}]$ \\
\hline Stage II Vs Stage III & $<0.001[\mathrm{sig}]$ \\
\hline Stage II Vs Stage IV & $<0.001[\mathrm{sig}]$ \\
\hline Stage III Vs Stage IV & $\mathbf{0 . 0 0 1 2}[\mathrm{sig}]$ \\
\hline
\end{tabular}

Table 6: Comparison of ALP levels in malignant and benign breast tumours :

\begin{tabular}{|c|c|c|c|c|c|}
\hline & \multicolumn{2}{|c|}{ Malignant } & \multicolumn{2}{|r|}{ Benign } & \multirow{2}{*}{$p$ value } \\
\hline & Mean & Std.Deviation & Mean & Std. Deviation & \\
\hline Serum ALP level & 98.3 & 51.4 & 75.48 & 29.20 & 0.001 \\
\hline
\end{tabular}

Table 7: Mean Serum ALP Level according to the clinical stage

\begin{tabular}{|c|c|c|c|}
\hline Stage & Mean Serum ALP & Std. Deviation & No of patients \\
\hline I & 63.33 & 19.43 & 3 \\
\hline II & 86.10 & 32.08 & 31 \\
\hline III & 89.38 & 26.95 & 37 \\
\hline IV & 188.33 & 91.36 & 9 \\
\hline
\end{tabular}

Table no. 8: Comparison of Mean Serum ALP Level in different clinical stages of breast cancer patients:

\begin{tabular}{|c|c|}
\hline ALP mean & P value \\
\hline Benign Vs stage I & 0.39 \\
\hline Stage I Vs Stage II & 0.16 \\
\hline Stage I Vs Stage III & 0.13 \\
\hline Stage I Vs Stage IV & $0.005[$ sig] \\
\hline Stage II Vs Stage III & 0.65 \\
\hline Stage II Vs Stage IV & $0.014[\mathrm{sig}]$ \\
\hline Stage III Vs Stage IV & $0.016[\mathrm{sig}]$ \\
\hline
\end{tabular}

Table 9: Correlation of Serum LDH with size of tumor in Malignant and benign lesions :

\begin{tabular}{|c|c|c|c|c|c|}
\hline Size $[\mathrm{cm}]$ & Type & Mean LDH & Std. Deviation & No of patients & P value \\
\hline \multirow{2}{*}{$<2$} & Malignant & 412.0 & & 1 & 0.55 \\
\hline & Benign & 482.2 & 113.0 & 29 & \\
\hline \multirow{2}{*}{$2-3$} & Malignant & 681.9 & 256.3 & 22 & $<0.001$ \\
\hline & Benign & 497.0 & 113.2 & 42 & \\
\hline \multirow{2}{*}{$4-5$. } & Malignant & 653.7 & 174.9 & 27 & 0.091 \\
\hline & Benign & 495.3 & 111.1 & 4 & \\
\hline \multirow{2}{*}{$>5$} & Malignant & 692.8 & 235.2 & 30 & 0.18 \\
\hline & Benign & 547.4 & 74.5 & 5 & \\
\hline
\end{tabular}

Table 10: Correlation of serum ALP with size of tumor in Malignant and benign lesions :

\begin{tabular}{|c|c|c|c|c|c|}
\hline Size $[\mathrm{cm}]$ & Type & Mean ALP & Std. Deviation & $\begin{array}{r}\text { No of } \\
\text { patients }\end{array}$ & $P$ value \\
\hline \multirow{2}{*}{$<2$} & Malignant & 68.0 & & 1 & 0.98 \\
\hline & Benign & 67.6 & 25.5 & 29 & \\
\hline \multirow{2}{*}{$2-3$} & Malignant & 106.8 & 67.3 & 22 & 0.038 \\
\hline & Benign & 80.6 & 32.1 & 42 & \\
\hline \multirow{2}{*}{ 4- 5.} & Malignant & 96.0 & 55.5 & 27 & 0.61 \\
\hline & Benign & 81.0 & 31.8 & 4 & \\
\hline \multirow{2}{*}{$>5$} & Malignant & 95.1 & 32.4 & 30 & 0.17 \\
\hline & Benign & 74.0 & 15.2 & 5 & \\
\hline
\end{tabular}




\section{V.Discussion}

Breast cancer is a major public health issue worldwide. According to GLOBOCAN 2012, 1.7 million women were diagnosed with breast cancer in the year 2012. Since the 2008 estimates, breast cancer incidence has increased by more than $20 \%$, while mortality has increased by $14 \%^{6}$. In India, for the year 2012 , 144,937 women were newly detected with breast cancer and 70,218 women died of breast cancer. ${ }^{17}$ The morbidity, mortality and overall cost for the treatment of patients with breast cancer increases with higher stage of disease and so screening and diagnosis of breast cancer in earlier stages helps the patient to reduce the suffering and minimizes the financial burden.

Many studies have tried to evaluate role of tumor markers in in diagnosis of carcinoma breast .In view of this present study was undertaken to study the serum levels of Lactate Dehydrogenase and Alkaline Phosphatase in cases of benign and malignant breast lesions and to evaluate whether serum levels of Lactate Dehydrogenase and Alkaline Phosphatase are significantly higher in cases of breast malignancies as compared to cases of benign breast lesions.

The present study included 80 cases of each benign and malignant lesions of breast (total 160 cases) confirmed cytologically or histopathologically during the period november 2014 to november 2015 in department of pathology , NSCB Medical College and Hospital , Jabalpur.

On distributing cases according to age it was seen that most lesions were in reproductive age group .Benign lesions were more common in younger age group (20 to 29 years) i.e. $33.8 \%$ (table 1). Our findings correlate with the study of Mudholkarer et al 2012 $11-21$ years of age group.

Malignant lesions were seen in older age group (40- 49 yrs) i.e 52.5\% (table 1). Similar findings were observed by Navneet Kaur et al ${ }^{8}$, maximum number of cases of carcinoma breast were in the age group of 3544 years and Ramchandra Kamath et $\mathrm{al}^{9}$, found the average age of cases of breast cancer was 45.64 years .

In present study the mean serum levels of LDH was $673.10 \pm 221.35 \mathrm{U} / \mathrm{L}$ in cases of Malignant lesions while in cases of Benign lesions the mean value was $494.69 \pm 110.29 \mathrm{U} / \mathrm{L}$. The mean value of serum LDH was raised significantly raised $(\mathrm{p}<0.001)$ in cases of malignant lesions when compared with those of benign lesions (table 3), which suggest an immense potential of LDH as a marker for Breast cancer .Our findings correlate with the study of Chandrakanth et al ${ }^{10}$, found mean serum LDH levels to be significantly elevated ( $p<0.001$ ) in breast cancer than in fibroadenoma cases.Similar findings were also observed by Anupama Shrinivasan et al ${ }^{11}$, Abdalla M Jarari et al ${ }^{12}$, Sandhya Mishra et $a l^{2}$, found significant elevation in serum levels of LDH as compared to controls .

When levels of serum LDH in these patients at various stages of Breast cancer were estimated it was observed that mean serum LDH levels increased significantly with stage of disease (from stage II to stage IV) (table 5) . Our findings are in accordance with Amritpal kaur et al ${ }^{13}$, Chandrakanth et al ${ }^{10}$, Seth L $R$ et al ${ }^{14}$, Anupama Shrinivasan et al ${ }^{11}$, they found serum LDH levels increased significantly with increasing severity of carcinoma breast (from stage I to stage IV ).

The serum levels of ALP were significantly high ( $\mathrm{p}$ value 0.001$)$ in patients of carcinoma breast $(98.3 \pm$ $51.4 \mathrm{U} / \mathrm{L})$ as compared to benign lesions $(75.48 \pm 29.20$ ) in present study (table 6). There was steady and progressive rise in serum levels of ALP from stage I to stage IV of breast cancer (table 7). However there was significant rise in ALP levels in stage IV when compared to other stages (table 8). Amritpal kaur et al ${ }^{13}$, Choudhari et al ${ }^{15}$, A $K$ Singh et al ${ }^{16}$ found the levels of serum ALP were significantly higher in patients of carcinoma breast as compared to controls and that there was progressive increase in serum ALP activities with advance in stage of disease and metastasis.

Malignant lesions were more common in rural areas as compared to urban in present study (table 2). This could be due to poor medical aid in rural areas , lower socioeconomic status and illiteracy.

In present study serum levels of LDH and ALP were higher in malignant cases as compared to benign with comparable size of the tumor (table 9,10). These enzymes may therefore be a supportive biochemical markers along with clinical and histopathological findings for guiding management in cases with suspicious diagnosis.

\section{Conclusion}

The present observational study has shown a significant elevation in serum levels of LDH and ALP in cases of carcinoma Breast and these estimations together with clinical and histopathological findings may serve as potential markers in assessing the prognosis, early detection of metastasis in patients of breast cancer. A serial measurement of these enzymes will have a prognostic significance and help treatment decisions. These enzymes can be easily assayed and are less expensive. Not only are these enzymes helpful to differentiate malignant growths from benign tumors, but also assist in assessing the extent and therefore prognosis of this malignancy along with clinical findings. 
It is difficult to ascertain their diagnostic importance in cancer patients yet their prognostic importance cannot be undermined. The increase in levels of serum ALP may be used as a diagnostic marker for early detection of metastasis

In this preliminary study it appears that serum LDH and ALP levels could be used as potential biochemical parameters in laboratories that do not have sophisticated technologies to measure tumor markers in breast cancer patients. The advantages of these parameters are that they are simple, accurate, cost effective and can be easily assayed in smaller laboratories which have not been exposed to any sophisticated technologies. If these findings are replicated in a larger study, with a larger sample size and follow up of the patients, they may afford a new and inexpensive opportunity to delineate women who are at high risk of breast cancer with the hope of targeting surveillance, allowing early detection of progression of disease and thereby reducing mortality occurring from this disease .

\section{References:.}

[1]. Chitkara N., Dadoo R.C. , Bansal S. et al. Plasma vitamin E levels in carcinoma Breast. Indian J clinical Biochem 1996 , 11: 162164 .

[2]. Mishra S. ,Sharma D.C. and Sharma P. , Studies of biochemical parameters in breast cancer with and without metastasis. Indian Journal of Clinical Biochemistry, 2004, 19 (1) 71-75.

[3]. Swetha N., Senghor K.A., Ramachandran K. ,Serum lactate dehydrogenase and lipid profile in breast cancer. International Journal of Pharmacy and Biological Sciences, 2013,3 (2) 423-432.

[4]. AbdolhassanTalaiezadeh, Ali Shahriari, Mohammad Reza Tabandeh , Payam Fathizadeh and Siavash Mansouri, Kinetic characterization of lactate dehydrogenase in normal and malignant human breast tissues Cancer Cell International 2015, 15:19.

[5]. Ismaeel A.A., Yousif N.F., Ali K.F. and. Mousa F.H, Antitumor Activity of New Quinoxaline Analogues and Its Complexes, Pak. J. Chem, 2013 , 3(4): 177-181.

[6]. Latest world cancer statistics 'Global cancer burden rises to 14.1 million new cases in 2012: Marked increase in breast cancers must be addressed.' Intenational agency for research on cancer. World Health Organization. Press release N ${ }^{\circ} 22312$ December 2013. [Last accessed on 2015 October15]. Available from http://www.iarc.fr/en/media-centre/pr/2013/pdfs/pr223_E.pdf.

[7]. Vishal G. Mudholkar , Seema B. Kawade , Subhash N. Mashal. Histopathological Study of Neoplastic Lesions of Breast, Indian Medical Gazette 2012, 353.

[8]. Navneet Kaur, Amit Attam, Sudipta Saha, S. K. Bhargava . Breast Cancer Risk Factor Profile in Indian Women. JIMSA , 2011, 24 (4).

[9]. Ramchandra Kamath, Kamaleshwar S Mahajan, Lena Ashok, and T S Sanal. A Study on Risk Factors of Breast Cancer Among Patients Attending the Tertiary Care Hospital, in Udupi District. Indian J Community Med. 2013, 38(2): 95-99.

[10]. Chandrakanth Nagaraj, Jayaprakash Murthy ,Satishkumar and Anand Pyati , Study of serum levels of gamma- glutamyl transferase, lactate dehydrogenase, malondialdehyde and vitamin-e in breast cancer. International journal of pharma and bio sciences .2011, 2 (4).

[11]. Anupama shrinivasan, Poongothai AR, Chandrasekhar Rao S, Shrinivasulu M. 'Serum Lactate Dehydrogenase (LDH) levels in Breast cancer.' Ind J Hum Genet 1999, 5(2) : 21-27.

[12]. Abdalla M Jarari, S.Shakila, Saeid Omer Alsoaeitiv, Nouh M H. Aljarari ,Anuradha.A, Jagannadha Rao Peela. Serum levels of LDH and Gamma GT in Libyan Breast Cancer patients. Indian journal of applied research, 2013, 3(12).

[13]. Amritpal Kaur, Mridula Mahajan and Sudhir Khichy. Biomarkers of carcinoma breast in females. International Journal of Recent Scientific Research, 2015 ,6(2) 2625-2629.

[14]. Seth LR, Kharb S, Kharb DP. Serum biochemical markers in carcinoma breast. Indian J Med Sci. 2003 ,57(8):350-4.

[15]. Choudhari A, Desai P, Indumati V, Kadi S. Activities of serum Ada, GGT and alp in carcinoma breast-a case control study for diagnostic and prognostic significance .Indian J Med Sci 2013;67:123-9.

[16]. Singh A.K., Pandey A. , Tewari M., Kumar R., Sharma A. , Singh K.A., Pandey H.P., and Shukla H.S. , Advanced stage of breast cancer hoist alkaline phosphatase activity: risk factor for females in India, Biotech. 2013 Dec; 3(6): 517-520.

[17]. Statistics of Breast cancer in India [Last accessed on 2015 october 15 ]Available from http://www. breastcancerindia.net/ statistics/ trends.html. 